\title{
Serum inorganic phosphorus levels predict 30-day mortality in patients with community acquired pneumonia
}

\author{
Mohammad E. Naffaa ${ }^{1,2,5}$, Mona Mustafa ${ }^{3}$, Mohje Azzam ${ }^{5}$, Roni Nasser ${ }^{1}$, Nizar Andria', Zaher S. Azzam ${ }^{4,5}$ \\ and Eyal Braun ${ }^{1,5,6^{*}}$
}

\begin{abstract}
Background: Community acquired pneumonia is a major cause of morbidity and mortality. The association between serum phosphorus levels on admission and the outcome of patients with community acquired pneumonia has not been widely examined. We aimed to investigate the prognostic value of serum phosphorus levels on admission on the 30- day mortality.

Methods: The cohort included patients of 18 years old or older who were diagnosed with community acquired pneumonia between 2006 and 2012. Patients were retrospectively analyzed to identify risk factors for a primary endpoint of 30-day mortality. Binary logistic regression analysis was used for the calculation of the odds ratios (OR) and $\mathrm{p}$ values in bivariate and multivariate analysis to identify association between patients' characteristic and 30-day mortality.
\end{abstract}

Results: The cohort included 3894 patients. In multivariate regression analysis, variables associated with increased risk of 30-day mortality included: age $>80$ years, increased CURB-65 score, RDW $>15$, hypernatremia $>150 \mathrm{mmol} / \mathrm{l}$, hypoalbuminemia $<2 \mathrm{gr} / \mathrm{dl}$ and abnormal levels of phosphorus. Levels of $<1.5 \mathrm{mg} / \mathrm{dl}$ and $>4.5 \mathrm{mg} / \mathrm{dl}$ were significantly associated with excess 30-day mortality, 38 \% (OR 2.9, Cl 1.8-4.9, P = 0.001) and $39 \%$ (OR 3.4, Cl 2.7-4.2, $\mathrm{P}=0.001)$, respectively. Phosphorus levels within the upper normal limits $(4-4.5 \mathrm{mg} / \mathrm{dl})$ were associated with higher mortality rates compared to levels between 1.5-3.5 mg/dl, the reference group, $24 \%$ (OR 1.9, Cl 1.5-2.4, P = 0.001).

Conclusions: Abnormal phosphorus levels on admission are associated with increased mortality rates among patients hospitalized with Community acquired pneumonia.

\section{Background}

Community acquired pneumonia (CAP) is among the leading causes of mortality and severe morbidity especially among elderly population. Despite the efficacy of modern antibiotic treatment, it still ranks as the sixth most common cause of death [1-3]. Prognostic scores, like the CURB65 score and the Pneumonia Patient Outcomes Research Team score, were developed to estimate the risk of adverse outcome in patients treated in emergency rooms in an attempt to determine who is at risk for an adverse outcome, and therefore should be hospitalized $[4,5]$.

\footnotetext{
* Correspondence: e_braun@rambam.health.gov.l

'Department of Internal Medicine H, Rambam Health Care Campus, Haifa, Israel

${ }^{5}$ The Rappoport's Faculty of Medicine, Technion, Haifa, Israel

Full list of author information is available at the end of the article
}

Phosphorus, as an essential component in the ATP molecule, plays a central role in the energy production . Serum phosphorus level disturbances in patients with pneumonia have been reported [6-9]. Hypophosphatemia is detected in $2-3 \%$ of the patients hospitalized with medical illness [10-12]. Commonly reported etiologies for hypophosphatemia include alcohol abuse and withdrawal, diabetic ketoacidosis, nutritional recovery, alkalotic states, accelerated erythropoiesis and gram negative sepsis [13-19]. Many drugs have also been reported to cause hypophosphatemia, the most common being methylprednisolone, epinephrine, albumin, terbutaline, theophylline, and diethylsilbesterol [20].

Hypophosphatemia is known to play an essential role in impaired chemotaxis, phagocytosis, and bactericidal activity of macrophages [21]. Hypophosphtemia can lead to

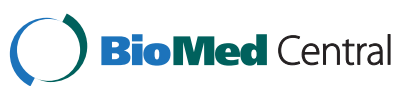


Table 1 Bivariate analysis of patients' characteristics associated with 30-day mortality

\begin{tabular}{|c|c|c|c|c|c|c|c|c|c|}
\hline \multicolumn{2}{|l|}{ Clinical RISK Factors } & \multicolumn{4}{|c|}{30 day-mortality } & \multirow[t]{2}{*}{ P-value } & \multirow[t]{2}{*}{ OR } & $95 \% \mathrm{Cl}$ & \\
\hline & & $\begin{array}{l}\text { Number } \\
3876\end{array}$ & $\begin{array}{l}\% \\
100 \%\end{array}$ & $\begin{array}{l}\text { Number } \\
674\end{array}$ & $\begin{array}{l}\% \\
17 \%\end{array}$ & & & & \\
\hline \multirow[t]{2}{*}{ Gender } & Female & 1664 & $43 \%$ & 282 & $17 \%$ & & Ref. & & \\
\hline & Male & 2212 & $57 \%$ & 392 & $18 \%$ & .529 & 1.056 & .892 & 1.249 \\
\hline \multirow[t]{6}{*}{ Age } & $<45$ & 271 & $7 \%$ & 13 & $5 \%$ & .000 & Ref. & & \\
\hline & $45-54$ & 209 & $5 \%$ & 12 & $6 \%$ & .252 & 1.490 & .753 & 2.947 \\
\hline & $55-64$ & 356 & $9 \%$ & 30 & $8 \%$ & .001 & 2.611 & 1.479 & 4.610 \\
\hline & $65-74$ & 579 & $15 \%$ & 74 & $13 \%$ & .000 & 3.187 & 1.876 & 5.416 \\
\hline & $75-84$ & 1016 & $26 \%$ & 163 & $16 \%$ & .000 & 5.387 & 3.247 & 8.936 \\
\hline & $\geq 85$ & 1445 & $37 \%$ & 382 & $26 \%$ & .000 & 8.864 & 5.326 & 14.753 \\
\hline \multirow[t]{3}{*}{ Year } & $2006-2008$ & 1730 & $45 \%$ & 289 & $17 \%$ & .230 & Ref. & & \\
\hline & 2009-2010 & 1058 & $27 \%$ & 202 & $19 \%$ & .109 & 1.177 & .965 & 1.435 \\
\hline & 2011-2012 & 1088 & $28 \%$ & 183 & $17 \%$ & .937 & 1.008 & .823 & 1.235 \\
\hline Charson's & No illnesses & 599 & $15.4 \%$ & 57 & $9.5 \%$ & .000 & 1 & & \\
\hline \multirow[t]{5}{*}{ Index } & 1 & 616 & $15.8 \%$ & 102 & $16.6 \%$ & .000 & 2.511 & 1.625 & 3.882 \\
\hline & 2 & 612 & $15.7 \%$ & 138 & $22.5 \%$ & .000 & 3.361 & 2.203 & 5.129 \\
\hline & $3-4$ & 1105 & $28.4 \%$ & 326 & $29.5 \%$ & .000 & 4.983 & 3.377 & 7.355 \\
\hline & $5-7$ & 723 & $18.6 \%$ & 245 & $33.9 \%$ & .000 & 5.291 & 3.541 & 7.906 \\
\hline & $8+$ & 239 & $6.1 \%$ & 108 & $45.2 \%$ & .000 & 8.678 & 5.522 & 13.637 \\
\hline \multirow[t]{6}{*}{ CURB-65 } & 0 & 589 & $15 \%$ & 11 & $2 \%$ & .000 & Ref. & & \\
\hline & 1 & 881 & $23 \%$ & 76 & $9 \%$ & .000 & 4.961 & 2.613 & 9.420 \\
\hline & 2 & 1286 & $33 \%$ & 192 & $15 \%$ & .000 & 9.222 & 4.981 & 17.073 \\
\hline & 3 & 826 & $21 \%$ & 257 & $31 \%$ & .000 & 23.733 & 12.838 & 43.875 \\
\hline & 4 & 263 & $7 \%$ & 120 & $46 \%$ & .000 & 44.094 & 23.157 & 83.959 \\
\hline & 5 & 31 & $1 \%$ & 18 & $58 \%$ & .000 & 72.755 & 27.708 & 184.387 \\
\hline
\end{tabular}

Abbreviations: OR Odds Ratio, $\mathrm{Cl}$ Confidence Interval, Ref. Reference

ATP depletion, a shift from oxidative phosphrylation toward glycolysis, and subsequently, organ dysfunction .and, especially, muscle weakness. Fisher et al found hypophosphatemia to be associated with longer hospital stay, but not with higher mortality in patients with respiratory illness [7]. Sankaran et al, on the other hand, reported that hypophosphatemic patients with pneumonia had longer hospital stay and higher mortality when compared with normophosphatemic patients [6].

In contrast to hypophosphatemia, the association between hyperphosphatemia and pneumonia has not been widely studied.Severe hyperphosphtemia may result in hypocalcemia which can cause tetany and pulmonary calcification. Saldias et al showed that hyperphosphatemia on admission represents a prognostic factor for in-hospital mortality in elderly patients with community acquired pneumonia [9].

In this cohort study, we aimed to examine the predictive prognostic value of serum phosphorus level on admission on the 30-day mortality in patients with community acquired pneumonia.

\section{Methods}

Patients aged 18 years old or older who were diagnosed with CAP and admitted to Rambam Health Care Campus, a tertiary medical center, between 1 January, 2006 and 31 December, 2012 were retrospectively and consecutively analyzed to identify risk factors for 30-day mortality. CAP was defined as pneumonia identified within the first 48 hours of hospitalization. The diagnosis of pneumonia was confirmed when the patient fulfilled the criteria suggested by Fang [22]. These criteria are as follows: $a$ ) infiltrate in a chest $x-$ ray taken on admission; $b$ ) the presence of one or more major findings (cough, mucopurulent or hemoptic expectoration, axillary temperature of over $37.8^{\circ} \mathrm{C}$ ); or $c$ ) at least two minor findings (pleuritic chest pain, dyspnea, decreased level of consciousness, lung tissue condensation observed in the physical lung examination, or a white blood count of over $12000 / \mathrm{mL}$ ). Protocol for treatment of CAP included either a combination of Ceftriaxone and Azithromycin or Levofloxacin as monotherapy. Data were collected from the Prometheus, an integrated computer system for handling patients' medical records. The 30-day mortality data were 
Table 2 Bivariate analysis of laboratory parameters associated with 30-day mortality

\begin{tabular}{|c|c|c|c|c|c|c|c|c|c|}
\hline \multirow{2}{*}{ Parameter } & & \multicolumn{4}{|c|}{30 day- mortality } & \multirow[t]{2}{*}{ P-Value } & \multirow[t]{2}{*}{ OR } & \multirow[t]{2}{*}{$95 \% \mathrm{Cl}$} & \\
\hline & & Number & $\%$ & $\mathrm{~N}$ & $\%$ & & & & \\
\hline & & 3,876 & $100 \%$ & 674 & $17 \%$ & & & & \\
\hline BUN (mg/dL) & $<20$ & 2754 & $71 \%$ & 298 & $11 \%$ & .000 & Ref. & & \\
\hline BUN (mg/dL) & $20-39$ & 485 & $13 \%$ & 134 & $28 \%$ & .000 & 3.15 & 2.494 & 3.970 \\
\hline BUN (mg/dL) & $40-59$ & 382 & $10 \%$ & 117 & $31 \%$ & .000 & 3.64 & 2.838 & 4.666 \\
\hline BUN (mg/dL) & $\geq 60$ & 255 & $7 \%$ & 125 & $49 \%$ & .000 & 7.92 & 6.029 & 10.416 \\
\hline Creatinine (mg/dL) & $0.9-1.29$ & 2258 & $58 \%$ & 288 & $13 \%$ & .000 & Ref. & & \\
\hline Creatinine (mg/dL) & $0.1-0.9$ & 142 & $4 \%$ & 27 & $19 \%$ & .034 & 1.606 & 1.037 & 2.486 \\
\hline Creatinine (mg/dL) & $1.3-1.49$ & 545 & $14 \%$ & 95 & $17 \%$ & .004 & 1.444 & 1.121 & 1.861 \\
\hline Creatinine (mg/dL) & $1.5-1.9$ & 455 & $12 \%$ & 106 & $23 \%$ & .000 & 2.078 & 1.618 & 2.668 \\
\hline Creatinine (mg/dL) & $\geq 2$ & 476 & $12 \%$ & 158 & $33 \%$ & .000 & 3.399 & 2.708 & 4.266 \\
\hline Hemoglobin & $\geq 12$ & 1911 & $49 \%$ & 235 & $12 \%$ & .000 & Ref. & & \\
\hline Hemoglobin & $10-11$ & 1307 & $34 \%$ & 243 & $19 \%$ & .000 & 1.664 & 1.404 & 1.972 \\
\hline Hemoglobin & $9-10$ & 380 & $10 \%$ & 99 & $26 \%$ & .000 & 2.819 & 2.222 & 3.577 \\
\hline Hemoglobin & $<9$ & 269 & $7 \%$ & 95 & $35 \%$ & .000 & 5.090 & 3.899 & 6.644 \\
\hline Hemoglobin & Missing & 9 & & 2 & $22 \%$ & & & & \\
\hline Albumin (g/dL) & $3.4-4$ & 513 & $13 \%$ & 21 & $4 \%$ & .000 & & & \\
\hline Albumin (g/dL) & $<2$ & 347 & $9 \%$ & 171 & $49 \%$ & .000 & 22.76 & 14.018 & 36.963 \\
\hline Albumin (g/dL) & $2-3$ & 1668 & $43 \%$ & 313 & $19 \%$ & .000 & 5.41 & 3.438 & 8.519 \\
\hline Albumin (g/dL) & $3-3.4$ & 721 & $19 \%$ & 55 & $8 \%$ & .012 & 1.93 & 1.155 & 3.242 \\
\hline Albumin (g/dL) & Missing & 627 & $16 \%$ & 114 & $18 \%$ & .000 & 5.21 & 3.217 & 8.427 \\
\hline Sodium (mmol/L) & $\leq 130$ & 412 & $11 \%$ & 76 & $18 \%$ & .000 & 1.00 & & \\
\hline Sodium (mmol/L) & $130-150$ & 3366 & $87 \%$ & 543 & $16 \%$ & .231 & 0.85 & .652 & 1.109 \\
\hline Sodium (mmol/L) & $\geq 150$ & 97 & $3 \%$ & 55 & $57 \%$ & .000 & 5.79 & 3.609 & 9.287 \\
\hline Sodium(mmol/L) & Missing & 1 & & 0 & $0 \%$ & & & & \\
\hline WBC $\left(10^{3} / \mu \mathrm{L}\right)$ & $4 \leq \leq 12$ & 1816 & $47 \%$ & 259 & $14 \%$ & .000 & Ref. & & \\
\hline WBC $\left(10^{3} / \mu \mathrm{L}\right)$ & $<4$ & 144 & $4 \%$ & 27 & $19 \%$ & .007 & 1.668 & 1.150 & 2.421 \\
\hline $\operatorname{WBC}\left(10^{3} / \mu \mathrm{L}\right)$ & $>12$ & 1907 & $49 \%$ & 386 & $20 \%$ & .000 & 1.529 & 1.315 & 1.777 \\
\hline WBC $\left(10^{3} / \mu \mathrm{L}\right)$ & Missing & 9 & & 2 & $22 \%$ & & & & \\
\hline Hematocrit (\%) & $\geq 30$ & 3268 & $85 \%$ & 496 & $15 \%$ & & Ref. & & \\
\hline Hematocrit (\%) & $<30$ & 599 & $15 \%$ & 176 & $29 \%$ & .000 & 2.735 & 2.280 & 3.280 \\
\hline Hematocrit (\%) & Missing & 9 & & 2 & $22 \%$ & & & & \\
\hline RDW (\%) & $\leq 15$ & 1958 & $59 \%$ & 242 & $12 \%$ & & 1.00 & & \\
\hline RDW (\%) & $>15$ & 1373 & $41 \%$ & 348 & $25 \%$ & .000 & 2.41 & 2.008 & 2.886 \\
\hline RDW (\%) & Missing & 545 & & 84 & $15 \%$ & & & & \\
\hline GFR (ml/min) & $\leq 90$ & 852 & $22 \%$ & 106 & $12.4 \%$ & .000 & 1.00 & & \\
\hline GFR (ml/min) & $60-90$ & 1227 & $32 \%$ & 149 & $12.1 \%$ & .839 & 0.97 & .746 & 1.269 \\
\hline GFR (ml/min) & $30-60$ & 1332 & $34 \%$ & 260 & $19.5 \%$ & .000 & 1.71 & 1.337 & 2.180 \\
\hline GFR (ml/min) & $15-30$ & 369 & $10 \%$ & 130 & $35.2 \%$ & .000 & 3.83 & 2.850 & 5.141 \\
\hline GFR (ml/min) & $<15$ & 96 & $2 \%$ & 29 & $30.2 \%$ & .000 & 3.05 & 1.883 & 4.927 \\
\hline Phosphorus (mg/dL) & $2.5-4.49$ & 2790 & $72 \%$ & 415 & $14.9 \%$ & .000 & 1.00 & & \\
\hline Phosphorus (mg/dL) & $\leq 2.49$ & 643 & $17 \%$ & 91 & $14.2 \%$ & .641 & 0.94 & .738 & 1.205 \\
\hline Phosphorus (mg/dL) & $\geq 4.5$ & 443 & $11 \%$ & 168 & $37.9 \%$ & .000 & 3.50 & 2.810 & 4.350 \\
\hline Phosphorus (mg/dL) & $1.51-3.9$ & 3004 & $78 \%$ & 396 & $13.2 \%$ & .000 & 1.00 & & \\
\hline
\end{tabular}


Table 2 Bivariate analysis of laboratory parameters associated with 30-day mortality (Continued)

\begin{tabular}{|c|c|c|c|c|c|c|c|c|c|}
\hline Phosphorus (mg/dL) & $\leq 1.5$ & 62 & $2 \%$ & 24 & $38.7 \%$ & .000 & 4.16 & 2.468 & 7.009 \\
\hline Phosphorus (mg/dL) & $4-4.49$ & 367 & $9 \%$ & 86 & $23.4 \%$ & .000 & 2.02 & 1.548 & 2.624 \\
\hline Phosphorus (mg/dL) & $\geq 4.5$ & 443 & $11 \%$ & 168 & $37.9 \%$ & .000 & 4.02 & 3.232 & 5.009 \\
\hline
\end{tabular}

Abbreviations: OR Odds Ratio, CI Confidence Interval, Ref. Reference, BUN Blood Urea Nitrogen, WBC White Blood Cells, RDW Red Blood Cell Distribution Width, GFR Glomerular Filtration Rate

retrieved from the database of our hospital and the ministry of health. Exclusion criteria included age under 18 years, transfer from another hospital, hospitalization during 30 days prior to admission, hospital-acquired pneumonia (defined as pneumonia which was diagnosed more than 48 hours after admission) or partial antibiotic treatment before hospitalization.

The following data were retrieved from the electronic medical records of the patients:

(1) Malignancies: solid tumors and hematologic malignancies. (2) Pulmonary diseases: bronchial asthma, chronic obstructive lung disease, interstitial lung disease, bronchiectasis, permanent tracheostomy, past history of thoracic radiotherapy, previous episode of pneumonia, and previous or current active smoker. (3) Immune suppression conditions: current chronic corticosteroid treatment, current or recent chemotherapy treatment, carrier of HIV, primary immune deficiency, history of bone marrow transplantation. (4) Cardiovascular diseases including patients with decompensated heart failure. (5) Chronic kidney disease including patients on dialysis. (6) Diabetes mellitus. (7) Liver cirrhosis. (8) Prior neurologic damage. (9) Chronic alcohol use. (10) Intravenous drug abuse. (11) Nursing house residents. The vital signs including heart rate, systolic blood pressure, respiratory rate, oxygen saturation and temperature were recorded on admission. The Charlson's comorbidity index was calculated based on the data collected. The Charlson's comorbidity index is a score that predicts the ten-year mortality for a patient who may have a range of comorbid conditions, (a total of 22 conditions), while each condition is assigned a score of $1,2,3$, or 6 , depending on the risk of dying associated with each condition. Scores are summed to provide a total score to predict mortality [23].

\section{Laboratory variables on admission}

Serum glucose, serum creatinine, sodium, hemoglobin, white blood count, Red blood cell Distribution width (RDW), pH, calcium, phosphorus, bicarbonate, partial pressure of $\mathrm{CO} 2$, lactate, blood urea nitrogen (BUN), and serum albumin were measured on admission.

Hemoglobin levels, mean corpuscular volume and RDW were measured on admission, using the Advia 120 Hematology Analyzer (Siemens Healthcare Diagnostics Deerfield, Illinois, USA). Glucose, BUN and creatinine levels were measured using the "Dimension" (Siemens
Healthcare Diagnostics Deerfield, Illinois, USA). The normal serum inorganic phosphorus range in the Rambam Health Care Campus laboratory is $2.5-4.5 \mathrm{mg} / \mathrm{dl}$. Hypophosphatemia is defined as levels below $2.5 \mathrm{mg} / \mathrm{d}$; whereas, levels above $4.5 \mathrm{mg} / \mathrm{dl}$ defines hyperphoshphatemia.

\section{Statistical analysis}

Bivariate logistic regression analysis was used for the calculation of the odds ratios (OR) with $95 \%$ Confidence Interval $(\mathrm{CI})$ and $P$ values in bivariate analysis to identify association between patient's characteristic and 30-day mortality. Multivariate forward stepwise logistic regression was performed to assess the relation between patient's characteristics: co-morbidities, laboratory results, and 30day mortality.

Variables were selected as candidates for the multivariate analysis on the basis of the level of significance of the bivariate association with 30 -day mortality $(P<0.1)$. Notably, there was no predilection in choosing serum phosphorus or any other variable in the statistical model.

The area under curve (AUC) was used as a measure of model of discrimination. The calibration of the prediction equation was assessed by comparing the observed and expected numbers of 30-day mortality. The HosmerLemeshow goodness-of-fit statistic was calculated. We calculated the Spearman's rank correlation coefficient to try to find out any correlation between variables that were found positive in the multivariate analysis. Two-tailed $P$ values of 0.05 or less were considered as statistically significant. All statistical analyses were performed using SPSS (Statistics Products Solutions Services; Armonk, New York, USA) 21.0 software for Windows; Redmond, Washington, USA.

The Rambam Hospital Institutional Review Board approved the study. The approval number is 0515-12-RMB. The need for informed consent was waived.

\section{Results}

Of the 5608 patients who were diagnosed with CAP in Rambam Health Care Campus between January 1, 2006 and December 31, 2012; 3876 patients had serum inorganic phosphorus levels were available within the first 24 hours of admission, and subsequently constituted our cohort. Of these 3876 patients, $57 \%$ were males with median age of 69.6 years. The 30-day mortality was $17 \%$ $(n=674)$. As shown in Table 1 , the 30 -day mortality was 
not significantly different between men and women. As well, the 30-day mortality each year was similar throughout the study period.

\section{Factors associated with 30-day mortality}

As depicted in Table 1; 674 patients died within 30 days. Patients who died were older and had higher Charlson's score reflecting more comorbid conditions. The year of diagnosis and inclusion did not influence the rate of 30-day mortality.

Table 2 shows the association between different laboratory parameters and 30-day mortality. When serum phosphorus levels were examined according to the normal laboratory range of our institution, that is, between 2.5 and $4.5 \mathrm{mg} / \mathrm{dl}$ and levels below $2.5 \mathrm{mg} / \mathrm{dl}$ representing hypophosphatemia and levels above $4.5 \mathrm{mg} / \mathrm{dl}$ representing hyperphosphatemia; only hyperphosphatemia, but not hypophosphatemia, was associated with increased mortality risk with odds ratio (OR), $95 \%$ confidence interval (CI) and P value as follows: OR-3.5 (95 \% CI 2.81-4.35, $\mathrm{P}<0.0001)$. According to the ROC curve, cutoff levels of 1.51 and $3.9 \mathrm{mg} / \mathrm{dl}$ were associated with significant change in specificity (Fig. 1). Therefore, we used levels between
1.51 and 3.9 as our new reference. Accordingly, the 30day mortality rate was $13.2 \%$ and increased to $38.7 \%$ 30-day mortality rate with OR-4.16 (95 \% CI 2.468-7.009, $\mathrm{P}<0.0001)$ in patient with levels $\leq 1.5 \mathrm{mg} / \mathrm{dl}$. Notably, levels between $4-4.49 \mathrm{mg} / \mathrm{dl}$ and $\geq 4.5 \mathrm{mg} / \mathrm{dl}$ were associated with $23.4 \%$ and $37.9 \%$ 30-day mortality rate with OR-2.02 (95 \% CI 1.548-2.6.24, P<0.0001) and OR-4.02 (95 \% CI 3.232-5.009, P < 0.0001), respectively. Figure 2 shows the correlation between different serum phosphorus levels and 30-day mortality.

\section{Relationship between Glomerular Filtration Rate (GFR), Phosphorus and Mortality}

As shown in Fig. 3, the predictive value of serum phosphorus levels on CAP outcome was maintained even after adjustment for GFR. Through all levels of GFR, hypophosphatemia and hyperphosphatemia were associated with increased mortality rates.

\section{Relationship between CURB-65, Phosphorus and Mortality} The predictive value of serum phosphorus levels on CAP outcome was maintained after adjustment for CURB-65 score. While obviously higher CURB-65 score was

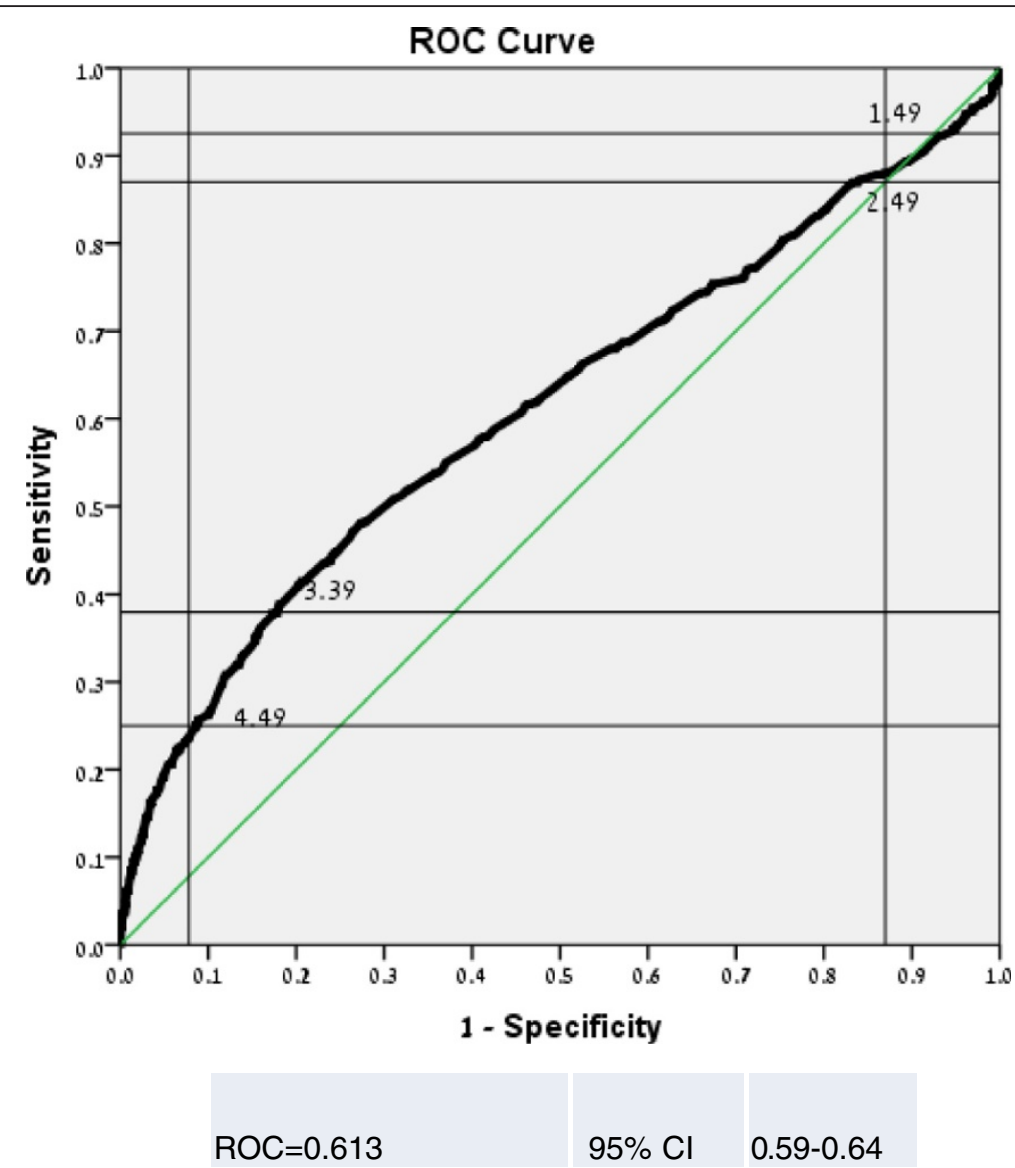

Fig. 1 Serum Phosphrus ROC Curve 


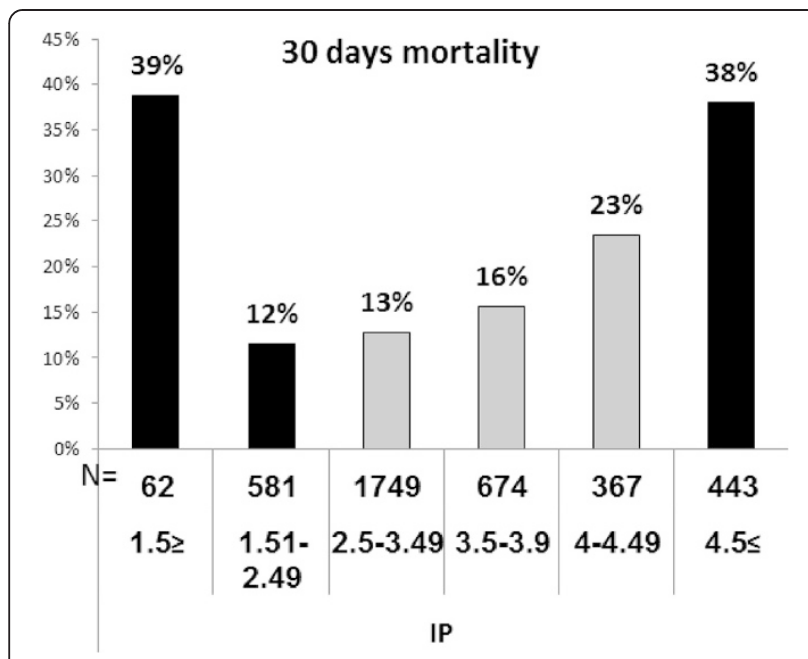

Fig. 2 30-day mortality according to phosphorus levels

associated with excess of mortality rates, severe hypophosphatemia and hyperphosphatemia were further associated with increased mortality rates for each CURB-65 score (Fig. 4).

\section{Relationship between Blood Urea Nitrogen (BUN), Phosphorus and Mortality}

As shown in Fig. 5, the predictive value of serum phosphorus levels on CAP outcome was maintained even after adjustment for BUN. Through all levels of BUN, hypophosphatemia and hyperphosphatemia were associated with increased mortality rates.
Multivariate analysis of factors associated with 30-day mortality

As shown in Table 3, the following factors were associated with higher rates of 30-day mortality: sodium $>150 \mathrm{meq} / \mathrm{l}$, RDW $>15$, low albumin levels $(<2)$ and age $>80$ years. Increasing CURB-65 scores were associated with higher mortality. Whenever serum phosphorus levels were added to the model, severe hypophosphtemia ( $<1.5 \mathrm{mg} / \mathrm{dl})$, levels between 4 and $4.5 \mathrm{mg} / \mathrm{dl}$, and especially levels above $4.5 \mathrm{mg} / \mathrm{dl}$ were associated with significant mortality. The addition of serum phosphorus levels to the model improved AUC/ROC curve from 0.747 (95\% CI = 0.7260.769 ) to 0.764 (95 \% CI=0.743-0.786). The HosmerLemeshow goodness-of-fit statistic was not statistically significant $(\mathrm{p}=0.77)$ indicating little departure and a perfect fit in both models.

In order to check for a possible correlation between serum phosphorus levels and other parameters, the sperman's correlation coefficient was calculated; however no significant correlation was found (Table 4).

\section{Discussion}

In this study, we examined the role of serum phosphorus levels as a predictor of 30-day mortality in patients admitted to medical wards because of CAP. Our study demonstrated that serum phosphorus level obtained within 24 hours from admission can predict 30-day mortality, with levels below $1.5 \mathrm{mg} / \mathrm{dl}$ and levels above $4.5 \mathrm{mg} / \mathrm{dl}$ being associated with increased mortality levels. It is remarkable to note that when we followed the conventional international definitions for hyperphosphatemia $(>4.5 \mathrm{mg} / \mathrm{dl})$ and hypophosphatemia $(<2.5 \mathrm{mg} / \mathrm{dl})$, only

\section{0 days mortality}

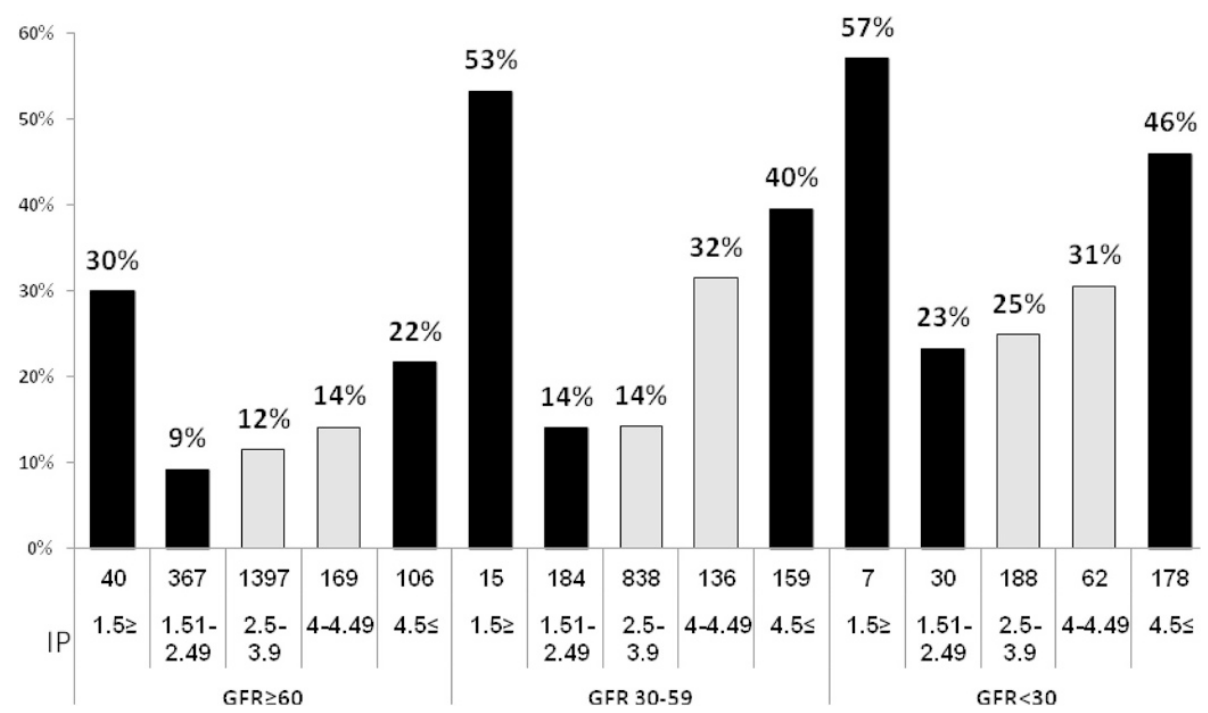

Fig. 3 The relationship between GFR, Phosphorus and Mortality 
30 days mortality

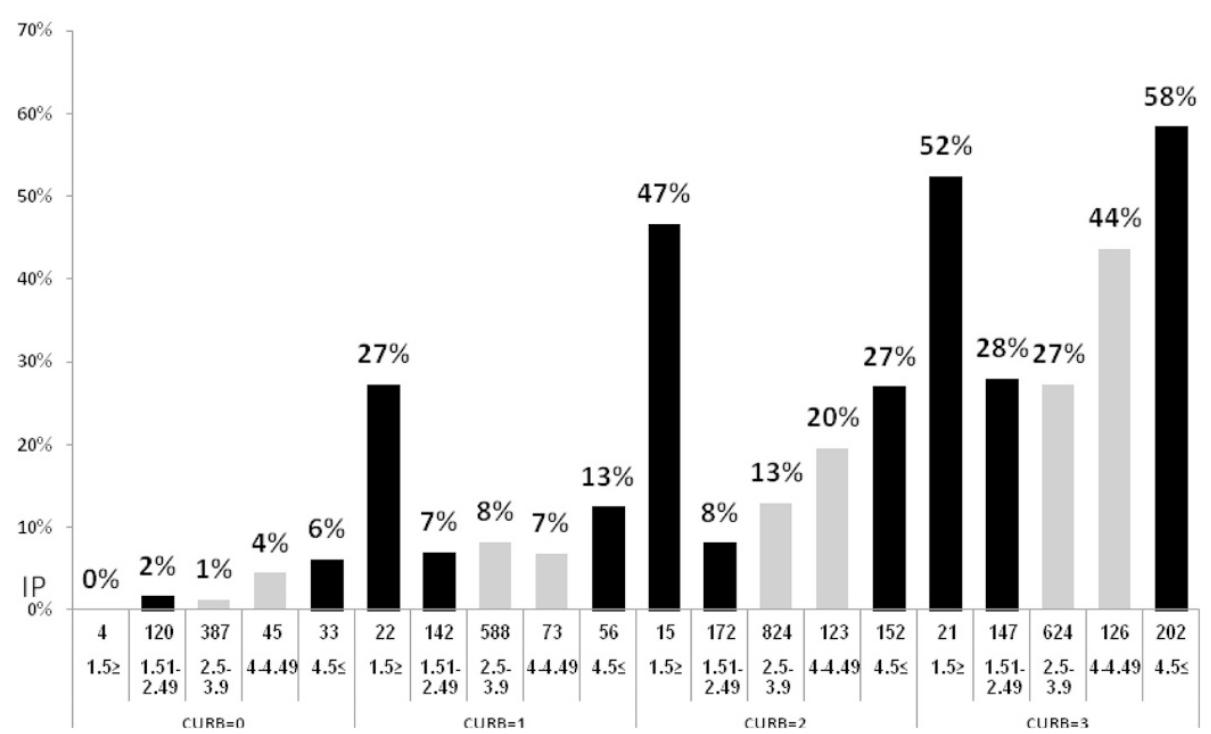

Fig. 4 The relationship between CURB-65, Phosphorus and Mortality

hyperphosphatemia was associated with increased mortality. However, when levels between 1.5-3.9 mg/dl constituted our reference group with 30-day mortality of $13.2 \%$; levels below $1.5 \mathrm{mg} / \mathrm{dl}$ and above $4.5 \mathrm{mg} / \mathrm{dl}$ were both associated with increased 30-days mortality, $38.7 \%$ and $37.9 \%$, respectively. Notably, even levels between $4-4.49 \mathrm{mg} / \mathrm{dl}$, that are considered to be normal according to laboratory standards, were associated with $23.4 \%$ 30-day mortality rates.

Phosphorus, as an essential component in the ATP molecule, plays a central role in the energy production. Therefore, depleted phosphorus stores, reflected by hypophosphatemia, might lead to insufficient and reduced ATP production which subsequently impairs several vital systemic functions including the immune system and the ability of the lungs to clear edema [24]. Craddock et al have shown that severe hypophosphatemia causes acquired phagocyte dysfunction reflected by defected chemotaxis, phagocytosis and bactericidal activity [21].

Hypophosphatemia in the setting of acute infectious illness such as CAP might have several etiologies, including refeeding, insulin therapy, acute respiratory alkalosis, inadequate intake, decreased phosphorus absorption

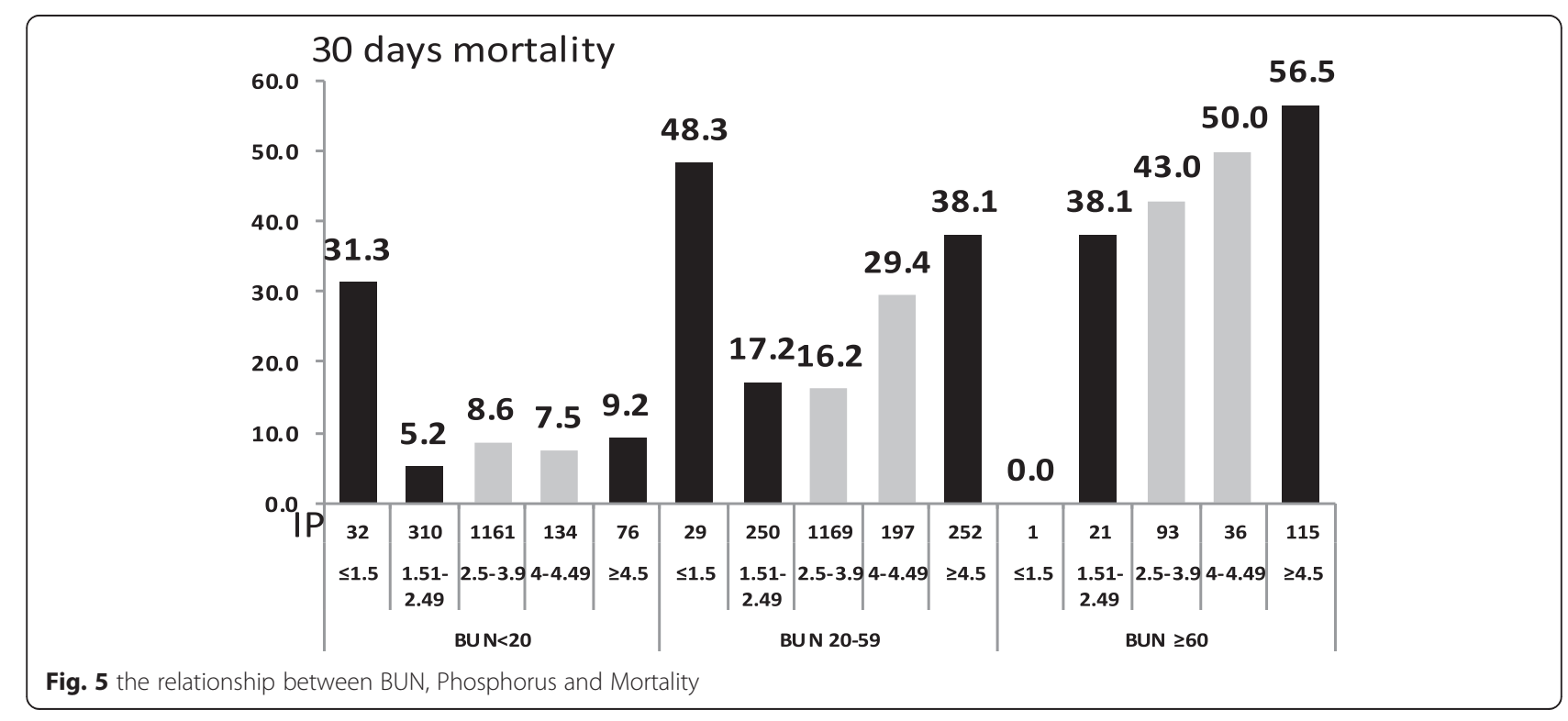


Table 3 Multivariate analysis of factors associated with 30-day

\begin{tabular}{|c|c|c|c|c|c|}
\hline \multirow[t]{2}{*}{ Parameter } & \multirow[t]{2}{*}{ Value } & \multirow[t]{2}{*}{ P-value } & \multirow[t]{2}{*}{ Adjusted OR } & \multicolumn{2}{|c|}{$95 \% \mathrm{Cl}$} \\
\hline & & & & Lower & Upper \\
\hline \multirow[t]{3}{*}{ CURB-65 } & $\leq 1$ & .000 & Ref. & & \\
\hline & 2 & .017 & 1.4 & 1.1 & 1.9 \\
\hline & $\geq 3$ & .000 & 3.5 & 2.6 & 4.7 \\
\hline Albumin (g/dL) & $<2$ & .000 & 3.8 & 2.9 & 5.0 \\
\hline RDW(\%) & $>15$ & .000 & 1.6 & 1.3 & 1.9 \\
\hline Sodium (mmol/L) & $\geq 150$ & .000 & 3.1 & 2.0 & 4.9 \\
\hline Age(years) & $\geq 80$ & .000 & 1.6 & 1.3 & 2.0 \\
\hline \multirow[t]{4}{*}{ Phosphorus (mg/dL) } & $1.51-3.9$ & .000 & Ref. & & \\
\hline & $\leq 1.5$ & .000 & 3.8 & 2.1 & 6.8 \\
\hline & $4-4.49$ & .001 & 1.7 & 1.3 & 2.3 \\
\hline & $\geq 4.5$ & .000 & 3.0 & 2.3 & 3.8 \\
\hline
\end{tabular}

Abbreviations: OR Odds Ratio, Cl Confidence Interval, Ref. Reference, RDW Red Blood Cell Distribution Width (eg. anti-acids), and the use of medications (eg. methylprednisolone, epinephrine, terbutaline, and theophylline) [13-20]. On the contrary, the causes of hyperphosphatemia in the acute setting of CAP are very few and usually include acute renal failure, phosphorus-containing medications and lactic or ketoacidosis. Di Marco et al have reported that high phosphorus levels can impair endothelial cell function at several levels including induction of sustained stiffening, increased apoptosis, impaired angiogenesis, impaired cell migration, downregulation of extracellular annexin II expression and shedding of endothelial microparticles [25]. Altogether, this suggests that hyperphosphatemia can interfere with normal function of the immune system.

Our study demonstrated that increased serum creatinine and urea levels were also associated with increased 30-day mortality, therefore, we aimed to examine whether the association between serum phosphorus levels and 30-day

Table 4 Spearman's Rank Correlation coefficient parameters

\begin{tabular}{|c|c|c|c|c|c|c|c|c|}
\hline & & & $\begin{array}{l}\% \text { of Pts with } \\
P \leq 1.5\end{array}$ & $\begin{array}{l}\text { \% of Pts with } \\
\text { P 1.51-2.49 }\end{array}$ & $\begin{array}{l}\text { \% of Pts with } \\
\text { P 2.5-3.99 }\end{array}$ & $\begin{array}{l}\% \text { of Pts with } \\
\text { P 4-4.49 }\end{array}$ & $\begin{array}{l}\% \text { of Pts with } \\
P \geq 4.5\end{array}$ & SPEARMAN \\
\hline \multirow[t]{6}{*}{ Age (years) } & $<40$ & 271 & 4 & 20 & 62 & 7 & 7 & 0.078 \\
\hline & $40-49$ & 209 & 2 & 15 & 65 & 11 & 7 & \\
\hline & $50-59$ & 356 & 1 & 21 & 58 & 8 & 11 & \\
\hline & $60-69$ & 579 & 1 & 16 & 62 & 9 & 11 & \\
\hline & $70-79$ & 1016 & 1 & 15 & 62 & 9 & 13 & \\
\hline & $\geq 80$ & 1445 & 2 & 12 & 64 & 10 & 12 & \\
\hline \multirow[t]{5}{*}{ Albumin $(\mathrm{g} / \mathrm{dL})$} & $3.4-4$ & 513 & 0 & 12 & 65 & 11 & 12 & 0.040 \\
\hline & $<2$ & 347 & 4 & 17 & 50 & 10 & 18 & \\
\hline & $2-3$ & 1668 & 1 & 15 & 62 & 8 & 12 & \\
\hline & $3-3.4$ & 721 & 1 & 14 & 66 & 10 & 9 & \\
\hline & Missing & 627 & 2 & 17 & 64 & 10 & 8 & \\
\hline \multirow[t]{4}{*}{ Sodium (mmol/L) } & $\leq 130$ & 412 & 2 & 19 & 61 & 7 & 12 & 0.049 \\
\hline & $130-150$ & 3366 & 2 & 15 & 63 & 10 & 11 & \\
\hline & $\geq 150$ & 97 & 1 & 12 & 55 & 13 & 19 & \\
\hline & Missing & 1 & 0 & 100 & 0 & 0 & 0 & \\
\hline \multirow[t]{7}{*}{ RDW (\%) } & $\leq 15$ & 1958 & 2 & 17 & 65 & 8 & 8 & 0.144 \\
\hline & $>15$ & 1373 & 1 & 11 & 59 & 11 & 17 & \\
\hline & Missing & 545 & 2 & 17 & 64 & 10 & 7 & \\
\hline & $60-90$ & 1227 & 2 & 18 & 67 & 8 & 5 & \\
\hline & $30-60$ & 1332 & 1 & 14 & 63 & 10 & 12 & \\
\hline & $15-30$ & 369 & 2 & 7 & 44 & 14 & 33 & \\
\hline & $<15$ & 96 & 0 & 5 & 25 & 11 & 58 & \\
\hline \multirow[t]{4}{*}{ CURB-65 } & 0 & 589 & 1 & 20 & 66 & 8 & 6 & \\
\hline & 1 & 881 & 2 & 16 & 67 & 8 & 6 & \\
\hline & 2 & 1286 & 1 & 13 & 64 & 10 & 12 & \\
\hline & 3 & 1120 & 2 & 13 & 56 & 11 & 18 & \\
\hline
\end{tabular}


mortality was related to renal failure. We reexamined the association between serum phosphorus levels and 30-day mortality after adjustment for GFR levels. As shown in Fig. 2, even after adjustment for GFR levels, serum phosphorus levels below $1.5 \mathrm{mg} / \mathrm{dl}$ and levels above $4 \mathrm{mg} / \mathrm{dl}$ were associated with increased 30-day mortality at each GFR subgroup. This indicates that serum phosphorus levels were associated with 30-day mortality regardless of GFR, creatinine or urea levels.

We also adjusted for CURB-65 score to evaluate whether serum phosphorus levels have an additional prognostic value. We showed that the prognostic value of serum phosphorus levels below $1.5 \mathrm{mg} / \mathrm{dl}$ and levels above $4 \mathrm{mg} / \mathrm{dl}$ was maintained at each CURB-65 score. Therefore, in levels below $1.5 \mathrm{mg} / \mathrm{dl}$, intravenous treatment of elemental phosphuros should be strongly considered.

In this study we reproduced our previous findings showing the elevated RDW is associated with increased mortality in patients with Community acquired pneumonia [26].

Our study has several limitations. The first is the retrospective design of the study. Secondly, data regarding the exact cause of 30-day mortality was not available in all cases and unfortunately, chest radiography appearance on admission was not included among the parameters examined. The third limitation was that not all patients admitted with CAP had serum phosphorus levels within 24 hours from admission. This may, in fact, reflect the fact that serum phosphorus levels were available for the more severe patients. This fact is consistent with our finding that the predictive value of serum phosphorus levels was greater in higher CURB-65 scores. Because of the retrospective nature of the study, data regarding vitamin D levels, Parathyroid hormone, Fibroblast growth factor-23 (FGF-23) levels and the urinary phosphorus excretion were not available. These vitamins and hormones are known to play a central role in the hemostasis of serum phosphorus, and might subsequently affect 30-day mortality. A fourth limitation was the lack exact information about antibiotic treatment pre admission; therefore, unfortunately, these patients were excluded.

\section{Conclusions}

Abnormal serum phosphorus levels on admission are associated with increased 30-mortality rates among adult patients hospitalized with CAP. The predictive value of phosphorus levels is maintained even after adjustment to GFR and CURB-65 levels.. We believe there is a real need to examine the prognostic predictive value of serum phosphorus levels on admission on 30-day mortality in patients with community acquired pneumonia prospectively, along with vitamin D levels, Parathyroid hormone, Fibroblast growth factor-23 (FGF-23) levels and the urinary phosphorus excretion.

\section{Abbreviations}

CAP: Community acquired pneumonia; OR: Odds ratio; Cl: Confidence interval; RDW: Red blood cell distribution width; GFR: Glomerular filtration rate; BUN: Blood urea nitrogen.

\section{Competing interests}

The authors declare that they have no competing interests.

\section{Authors' contributions}

MEN had full access to all of the data in the study and takes responsibility for the integrity of the data and the accuracy of the data analysis, contributed substantially to the study design, data analysis and interpretation, and the writing of the manuscript. MM took part in data acquisition and the writing of the manuscript. MA took part in data acquisition and the writing of the manuscript. RN took part in data acquisition and the revising of the manuscript. NA took part in data acquisition and the revising of the manuscript. ZSA contributed substantially to the study design, data analysis and interpretation, and the revising of the manuscript. EB had full access to all of the data in the study and takes responsibility for the integrity of the data and the accuracy of the data analysis, contributed substantially to the study design, data analysis and interpretation, and the writing of the manuscript. All authors read and approved the final manuscript.

\section{Author details}

${ }^{1}$ Department of Internal Medicine H, Rambam Health Care Campus, Haifa, Israel. ${ }^{2}$ B. Shine Rheumatology Unit, Rambam Health Care Campus, Haifa, Israel. ' ${ }^{3}$ epartment of Internal Medicine E, Rambam Health Care Campus, Haifa, Israel. ${ }^{4}$ Department of Internal Medicine B, Rambam Health Care Campus, Haifa, Israel. ${ }^{5}$ The Rappoport's Faculty of Medicine, Technion, Haifa, Israel. 'Department of Internal Medicine $\mathrm{H}$ and Infectious Diseases Unit, Rambam Health Care Campus, Haa'leya Hashneyya 8, Haifa 31096, Israel.

Received: 20 January 2015 Accepted: 6 August 2015

Published online: 13 August 2015

\section{References}

1. Fry AM, Shay DK, Holman RC, Curns AT, Anderson LJ. Trends in hospitalizations for pneumonia among persons aged 65 years or older in the United States, 1988-2002. JAMA. 2005;14(21):2712-9.

2. Garibaldi RA. Epidemiology of community-acquired respiratory tract infections in adults. Incidence, etiology and impact. Am J Med. 1985;14(6B):32-7.

3. Trotter CL, Stuart JM, George R, Miller E. Increasing hospital admissions for pneumonia, England. Emerg Infect Dis. 2008;14(5):727-33.

4. Renaud B, Labarère J, Coma E, Santin A, Hayon J, Gurgui M, et al. Risk stratification of early admission to the intensive care unit of patients with no major criteria of severe community-acquired pneumonia: development of an international prediction rule. Crit Care. 2009;14(2):R54.

5. Fine MJ, Auble TE, Yealy DM, Hanusa BH, Weissfeld LA, Singer DE, et al. A prediction rule to identify low-risk patients with community-acquired pneumonia. N Engl J Med. 1997;14(4):243-50.

6. Sankaran RT, Mattana J, Pollack S, Bhat P, Ahuja T, Patel A, et al. Laboratory abnormalities in patients with bacterial pneumonia. Chest. 1997;111:595-600

7. Fisher J, Magid N, Kallman C, Fanucchi M, Klein L, McCarthy D, et al. Respiratory illness and hypophosphatemia. Chest. 1983;83:504-8.

8. Newman JH, Neff T, Ziporin P. Acute respiratory failure associated with hypophosphatemia. N Engl J Med. 1977;296:1101-3.

9. Saldías Peñafiel F, O'Brien Solar A, Gederlini Gollerino A, Farías Gontupil G, Díaz Fuenzalida A. Community-acquired pneumonia requiring hospitalization in immunocompetent elderly patients: clinical features, prognostic factors and treatment. Arch Bronconeumol. 2003;39(8):333-40.

10. Betro MG, Pain RW. Hypophosphatemia in a hospital population. BMJ. 1972;1:273-6.

11. Hodkinson HM. Serum inorganic phosphate in a geriatric in-patient population. Gerontol Clin. 1973;15:45-9.

12. Rayback RS, Eckardt MJ, Pantler CP. Clinical relationship between serum phosphorus and other blood chemistry values in alcoholics. Arch Intern Med. 1980;140:673-7

13. Guillou PJ, Morgan DB, Hill GL. Hypophosphatemia: a complication of 'innocuous dextrose-saline'. Lancet. 1976;2:710-2. 
14. Juan D, Elrezak MA. Hypophosphatemia in hospitalized patients. JAMA 1979;242:163-4.

15. Shoenfeld Y, Hager S, Berliner S, Gallant LA, Pinkhas J. Hypophosphatemia as diagnostic aid to sepsis: study of 141 patients. NY State J Med. 1982;82:163-5

16. Knochel J. The pathophysiology and clinical characteristics of severe hypophosphatemia. Arch Intern Med. 1977;137:203-20.

17. Fitzgerald F. Clinical hypophosphatemia. Ann Rev Med. 1978;29:177-89.

18. Stoff JS. Phosphate homeostasis and hypophosphatemia. Am J Med. 1982;72:489-95.

19. Mohammed S, Knoll S, Van Amburg III A, Mennes PA. Cefotetan-induced hemolytic anemia causing severe hypophosphatemia. Am J Hematol. 1994:46:369-70.

20. Rapoport S, Stevens CD, Engel GL, et al. The effect of voluntary overbreathing on the electrolyte equilibrium of arterial blood in man. J Biol Chem. 1946;163:411-27.

21. Craddock PR, Yawata Y, VanSanten L, Gilberstadt S, Silvis S, Jacob HS Acquired phagocyte dysfunction: a complication of the hypophosphatemia of parenteral hyperalimentation. N Engl J Med. 1974;290:1403-7.

22. Fang GD, Fine M, Orloff J. New and emerging etiologies for community-acquired pneumonia with implications for therapy. A prospective multicenter study of 359 cases. Medicine (Baltimore). 1990;69:307-16.

23. Charlson ME, Pompei $P$, Ales $K L$, MacKenzie CR. "A new method of classifying prognostic comorbidity in longitudinal studies: development and validation". J Chronic Dis. 1987;14(5):373-83.

24. Berger G, Guetta J, Klorin G, Badarneh R, Braun E, Brod V, et al. Sepsis impairs alveolar epithelial function by downregulating Na-K-ATPase pump. Am J Physiol Lung Cell Mol Physiol. 2011;301(1):L23-30.

25. Di Marco GS, Konig M, Stock C. High phosphate directly affects endothelial function by downregulating annexin II. Kidney Int. 2013;83(2):213-22.

26. Braun E, Domany E, Kenig Y, Mazor Y, Makhoul BF, Azzam ZS. Elevated red cell distribution width predicts poor outcome in young patients with community acquired pneumonia. Crit Care. 2011;15(4):R194.

\section{Submit your next manuscript to BioMed Central and take full advantage of:}

- Convenient online submission

- Thorough peer review

- No space constraints or color figure charges

- Immediate publication on acceptance

- Inclusion in PubMed, CAS, Scopus and Google Scholar

- Research which is freely available for redistribution 